\title{
Article \\ Effect of Laser Pulses and Energy on the Structural Properties of ZnO Thin Film Prepared Using PLA Technique
}

\author{
Alaa Jabbar Ghazai ${ }^{1, *}$, Wisam, J. Aziz ${ }^{2}$ and Nedaa Taha Yassen ${ }^{1}$ \\ 1 Physics Depatment, Scince college, AlNahrain University, Iraq; mohnsh2006@gmail.com \\ 2 Physics Depatment, Scince college, AlMustansiryha University, Iraq; wisam_jaafer@yahoo.com \\ * Correspondence: alaaphys74@gmail.com.
}

\begin{abstract}
In this work, zinc oxide $(\mathrm{ZnO})$ thin film has been fabricated on glass substrate using pulse laser ablation (PLA) technique. The effect of laser pulses of 1000, 1500, 2000 pulses at laser energy $700 \mathrm{~mJ}$ as well as, laser energy of 600,700 , and $800 \mathrm{~mJ}$ at fixed laser pulses of 1500 pulse, with methanol as a solvent on the structural properties of prepared films using XRD, SEM and EDX. XRD results revealed that the $\mathrm{ZnO}$ thin films have hexagonal structure with polycrystalline in nature with preferred orientation of (002). Crystalline size was increased with the increasing of the pulses and at energy of $700 \mathrm{~mJ}$ and pulse of 1500 pulse seemed nanostructure like tree leaf. In addition, narrow FWHM and no phase change have been observed in all cases. SEM images showed that for all cases the films were homogenous with some island and cluster then cracking started to obtain with the increasing of increase the pulse number. EDX analysis showed that the prepared films were free of defects and contaminations.
\end{abstract}

Keywords: ZnO; pulse laser ablation (PLA); laser pulses; laser energy; nanoparticle

\section{Introduction}

Zinc oxide $(\mathrm{ZnO})$ has many promising properties for optoelectronics, sensor applications, and transparent electronics and so on, since it has a wide band gap energy and large exciting binding energy of $60 \mathrm{mV}$ at room temperature. There are two routes to produce a nanomaterials are: a topdown approach and a bottom-up approach. The idea behind the top-down approach is as following: An operator first designs and controls a macroscale machine shop to produce an exact copy of itself, but smaller in size such as laser ablation in liquid and chemical etching. While, the bottom-up approach is that one starts with atoms or molecules, which build up to form larger structures such as pulse laser deposition (PLD) and physical vapor deposition (PVD). However, the top-down approach is not expensive and rapid way of producing nanostructures [1]. The literatures on $\mathrm{ZnO}$ thin films started early and many researchers studied its physical properties, however, In (2001), Singh et al. prepared highly conductive and transparent Al-doped zinc oxide ( $\mathrm{ZnO}: \mathrm{Al}$ ) thin films by (PLA) technique with irradiation time of 10-60 min (6000-36000 laser shots)[2]. Then, in (2006), Yoshie Ishikawa, et al. successfully, produced zinc oxide nanorods using (PLA) in deionized water media at high temperature and at room temperature [3]. In addition, Chen and Zhang Prepared Nano-ZnO thin film by PLA and studied different factors that effect on the prepared films. Besides[4], in (2007), Thareja and Shukla formatted colloidal suspension of zinc oxide nanoparticles by (PLA) of a zinc metal target at room temperature in different liquid environment[5]. In (2008), Ajimsha et al. prepared $\mathrm{ZnO}$ quantum dots (QDs) in various liquid media using LP-PLA without using any surfactant. They concluded that, the emission wavelength was tuned due to the defect and varying in the laser fluency. After that [6], in (2009), Cho et al. produced ZnO Nanoparticles by (PLA) in deionized water. They revealed that there are strong in fluency of parameters such as, laser power, ablation time, and aging[7]. In (2010), Virt, et al. studied the properties of $\mathrm{ZnO}$ and $\mathrm{ZnMnO}$ thin films prepared by (PLA) that have polycrystalline behavior with average sizes of particles of $\mathrm{ZnMnO}$ film 
at $300 \mathrm{~K}$ and at $473 \mathrm{~K}$ were $50 \AA$ and $400 \AA$, respectively [8]. In (2011), Raid, et al. synthesized ZnO by (PLA) in double distilled water with various laser fluencies at RT. They founded that, the optical properties, size, and the morphology of prepared $\mathrm{ZnO}$ have influenced by laser fluency and wavelength [9]. In (2012), Atanasova, et al. prepared of $\mathrm{ZnO}$ nanostructure by (PLA) and some changes occurring on the surface of the films after continued exposure in air [10]. In (2013), Nakamura, et al. succeeded in synthesized $\mathrm{ZnO}$ nanoparticle by (PLA) method by Q-switched Nd:YAG laser in the air with spheres shape of diameters 10-20 $\mu \mathrm{m}$ [11]. In (2015), Fadhil and Hadi prepared zinc oxide nanoparticles by (PLA) of in isopropanol at room temperature at different laser fluency [12]. In (2016), Salim et al. fabricated ZnO Nanoparticles using LP-PLA system at a different laser wavelength $(1.06$ and $0.532 \mu \mathrm{m})$, laser fluency and number of the laser pulse. They studied the effect of these parameters on surface morphology and found that the grain size of the films increased with laser fluency and decreased with number of laser pulses [13]. In (2016), Farahan, et al. prepared $\mathrm{ZnO}$ nanoparticles by (PLA) and studied the effect of solvents (methanol and distilled water) on the characterization of $\mathrm{ZnO}$. They found that the $\mathrm{ZnO}$ nanoparticles have a hexagonal crystal structure and different size was formed due to the change of environment of laser pulse. Additionally [14], Ismail, et al. synthesized of pure and Er+3 doped $\mathrm{ZnO}$ nanoparticles by using (PLA) in ethanol at room temperature and found that the surface in granular morphology [15]. Late, in (2017), Khashan and Mahdi. Synthesized ZnO: Mg nanocomposite by (PLA) in liquid and they found that, the sample has hexagonal wurtzite [16].

To fabricate zinc oxide nanostructures where, pulsed laser ablation (PLA) has been used .In this work PLA of a solid target in liquid media is becoming an increasingly popular approach for controlled synthesis of noble metal and metal oxide nanoparticle. It is a chemically simple and clean synthesis method, due to reduced by-product formation, simpler starting materials and there is no need for a catalyst [17].

\section{Materials and Methods}

\subsection{Laser Ablation System}

The experimental setup for laser ablation, which includes Nd:YAG laser of $1064 \mathrm{~nm}$ were used for laser ablation process have been shown in Figure 1. The ablation process is done at room temperature. The target ( $\mathrm{Zn}$ ) (purity of $99.99 \%$ ) has been immersed in water or aqueous solution, and fixed at bottom of glass vessel container.

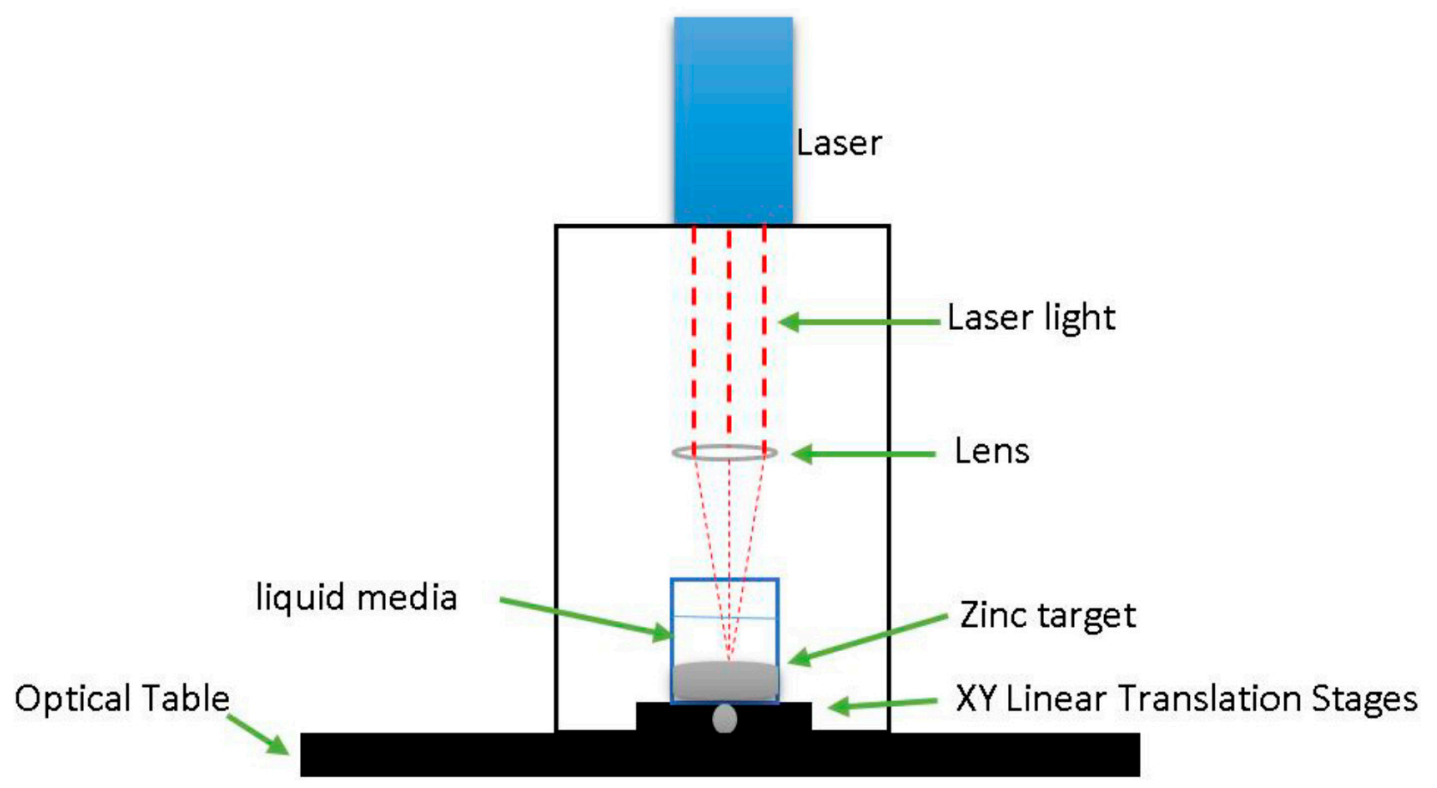

Figure 1. Experimental setup for nanoparticles synthesis by PLA process [12] 


\subsubsection{Laser Ablation Source}

$\mathrm{Nd}$ :YAG laser system type HUAFEI providing pulses at $1064 \mathrm{~nm}$ wavelength in the visible was used for ablation of target with pulse duration is $10 \mathrm{~ns}$, repetition rate of $1 \mathrm{~Hz}$ and effective beam diameter of $4.8 \mathrm{~mm}$, were used for laser ablation. The number of laser pulse ranged 1000, 1500, and 2000 pulses at energy of $700 \mathrm{~mJ}$ and laser energy of 600,700, and $800 \mathrm{~mJ}$ at 1500 pulse have been used in this work. Glass container was applied as a cell. The $\mathrm{Zn}$ target was placed on the bottom of glass container loaded with $3 \mathrm{ml}$ of distilled water. The solution profundity was around $3 \mathrm{~mm}$ during laser ablation. The cell holder that round at $9 \mathrm{rpm}$ was used to round the cell and its contents during ablation process to provide uniform ablation in order to ensure identical irradiation conditions for the subsequent pulses during laser exposure. Furthermore to avoid a deep ablation trace and craters formation onto the target surface due to repeated laser pulses on same spot and this rotation also helps to mix the solution, identical the optical path for the laser in the fluid.

\subsubsection{Solvents Types}

Absolute ethanol with purity $96 \%$ was used as ablation medium, compared to other solvents, ethanol provides a relatively inert environment for the production of nanoparticles. Also it has special property to exclude the oxide layer and to prevent the nanoparticles from oxidation.

\subsubsection{Substrate Preparation}

The substrate used for deposits $\mathrm{ZnO}$ thin films in this work is a glass slides with dimensions $(2.5 \times 2.5) \mathrm{cm}^{2}$. The cleaning of the substrate is very important because it has a great effect on the properties of the films. Firstly, cleaning the glass slides by using tap water to remove any dust that might be on the surface of the substrate and then they are placed in distilled water for 60 minutes. Then, Immersing the substrates in a pure acetone solution which reacts with contamination such as grease and some oxides, this process is fulfilled accurately by rewashing the substrates in the ultrasonic bath for 10 minutes and drying the slides by wiping them with soft paper.

\subsection{Preparation of Target}

The solid Zn target was taken from Fluka Company, united-states, product in 2015 with high purity (99.999\%). The sheet of tin firstly cut into small piece with dimensions of $1 \times 1 \mathrm{~cm}^{2}$ then polished and cleaned using HF-water (ration 1-50) before the ablation operation.

\subsection{ZnO Nanoparticles Formation}

The combination of ZnO NPs utilizing pulse laser ablation as a part of fluid can be compressed as the accompanying rigid $\mathrm{Zn}$ target was immersed at room temperature in glass container loaded with $3 \mathrm{ml}$ of liquid was placed on top cell holder and was irradiated by Nd-YAG laser operating at $1064 \mathrm{~nm}$ wavelength with the time of ablation are visually noted with the variation of color of the prepared colloids, a colloidal solution containing NPs was obtained and then characterized. The rapid reactive quenching and aqueous oxidation of highly active $\mathrm{Zn}$ bunches in fluid media is in charge of the development of $\mathrm{ZnO}$ nanoparticles. The colloidal was vibrated for 15 minute before deposition by ultrasonic vibrator in order to get homogeneity of the product. It is simply based on covering the substrate with three of drops or more of the solution and leaving it for a while to dry which used the hot plate (magnetic stirrer) at $80 \mathrm{C}^{\circ}$ temperatures.

\section{3- Results and Discussion}

\subsection{Structural properties of $\mathrm{ZnO}$ thin films}

Figure (2) shows the XRD pattern of $\mathrm{ZnO}$ nanoparticle on glass substrate with laser pulses number of 1000, 1500, and 2000 pulse at energy of $700 \mathrm{~mJ}$ in methanol, which revealed that the ZnO films have hexagonal polycrystalline structure nature with lattice parameter $c=5.130,5.159$ and 5.162 
respectively. Figure show that the diffraction peaks of $\mathrm{ZnO}$ nanoparticle were at $34.42^{\circ}, 36.25^{\circ}$ and $47.53^{\circ}$, which corresponding to the orientations of $\left(\begin{array}{lll}0 & 0 & 2\end{array}\right),\left(\begin{array}{lll}1 & 0 & 1\end{array}\right)$ and $\left(\begin{array}{lll}1 & 0 & 3\end{array}\right)$. These results are agreement with those given in JCPD data card and it is clear that there is no change in phase.

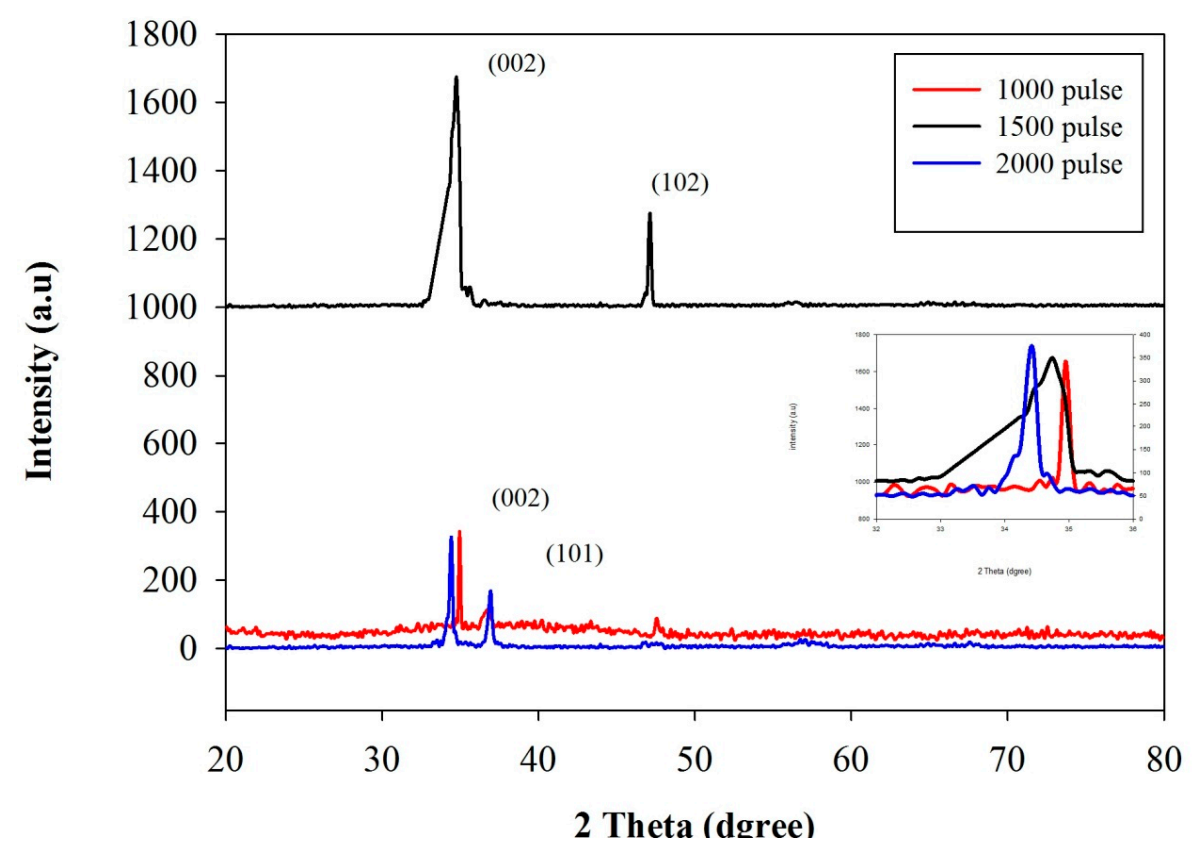

Figure (2): XRD pattern of ZnO nanoparticle on glass substrate with laser pulses number of 1000, 1500, and 2000 pulse at energy $700 \mathrm{~mJ}$ methanol solvent

Figure (3) shows the XRD pattern of $\mathrm{ZnO}$ nanoparticle on glass substrate with laser pulse number of 1500 pulse at energy of 600, 700 and $800 \mathrm{~mJ}$ dissolved in methanol. This Figure revealed that the $\mathrm{ZnO}$ films have hexagonal polycrystalline structure nature with lattice parameter $\mathrm{c}=5.130$, $5.159^{\circ}$ and $5.130^{\circ}$ respectively. Figure show that the diffraction peaks of $\mathrm{ZnO}$ nanoparticle on glass substrate were at $34.77^{\circ}$ and $36.17^{\circ}$, which corresponding to the orientations of $\left(\begin{array}{lll}0 & 0 & 2\end{array}\right)$, and $\left(\begin{array}{lll}1 & 0 & 1\end{array}\right)$. These results are agreement with those given in JCPD data card and it is clear that there is no change in phase.

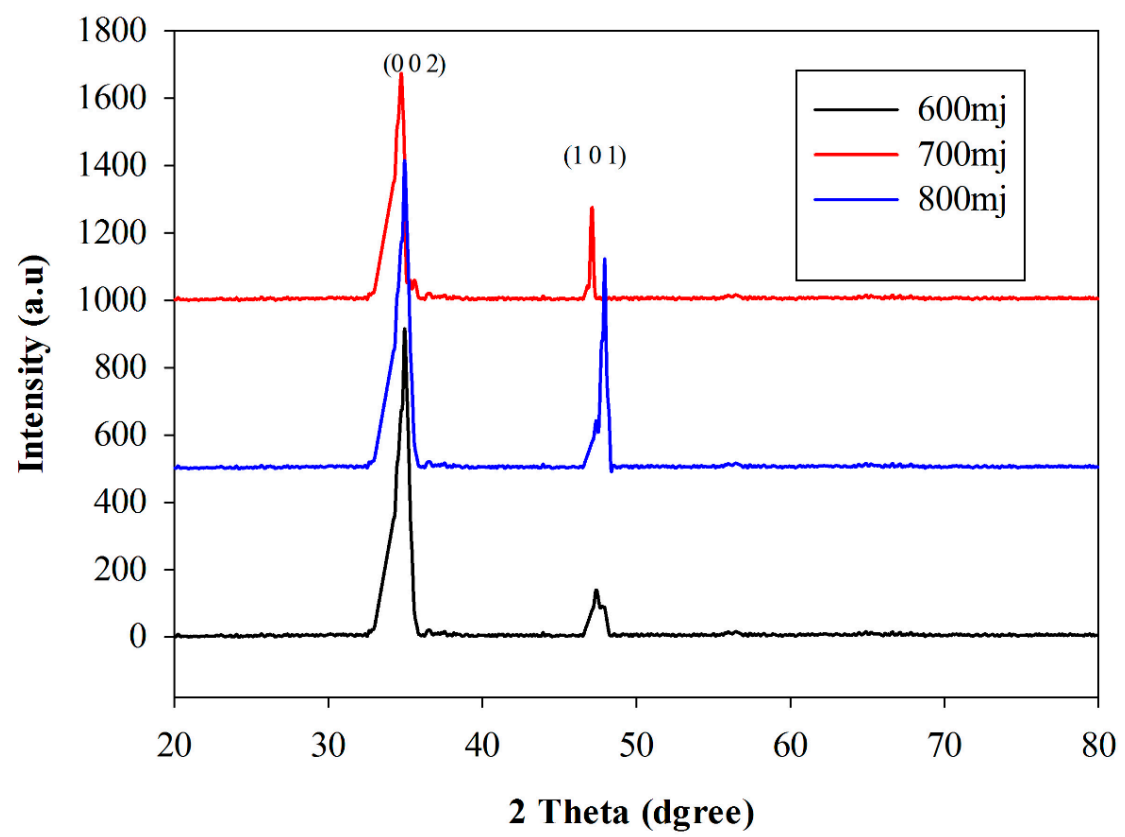

Figure (3): XRD pattern of $\mathrm{ZnO}$ nanoparticle on glass substrate with laser pulses number of 1500 pulse at energy $600 \mathrm{mj}, 700 \mathrm{~mJ}$ and $800 \mathrm{mj}$. 
Table (1): Structure parameters of $\mathrm{ZnO}$ nanoparticle on glass substrate with laser pulses number of 1000, 1500, and 2000 pulse at energy $700 \mathrm{~mJ}$ methanol solvent

\begin{tabular}{ccccccc}
\hline Pulses & $\begin{array}{c}\text { Position }(\mathbf{2} \\
\text { theta) }\end{array}$ & $\begin{array}{c}\text { Lattice } \\
\text { constant (c) } \\
(\mathbf{n m})\end{array}$ & FWHM & $\begin{array}{c}\text { Crystalline size } \\
\mathbf{( n m )}\end{array}$ & Strain & $\begin{array}{c}\text { Dislocation } \\
\text { density }\end{array}$ \\
\hline \multicolumn{7}{c}{ at laser energy of $700 \mathrm{~mJ}$} \\
1000 & 34.95 & 5.130902 & 0.055721 & 2.607609 & 0.01329 & 0.147067 \\
1500 & 34.75 & 5.159515 & 0.03263 & 4.450524 & 0.00779 & 0.050487 \\
2000 & 34.45 & 5.200524 & 0.041883 & 5.87444 & 0.00059 & 0.00029 \\
600 & 34.95 & & 0.055721 & 2.97642 & 0.01329 & 0.147067 \\
700 & 34.75 & 5.15697 & 0.03263 & 2.86873 & -.00779 & 0.050487 \\
800 & 34.95 & 5.12838 & 0.055721 & 2.97642 & 0.01329 & 0.147067 \\
\hline
\end{tabular}

Figure (4) show SEM images of ZnO nanoparticle prepared using PLA with pulse laser ablation, at fixed energy of $700 \mathrm{mj}$ and different Pulses of 1000, 1500 and 2000 dissolved in methanol solution and deposition on glass substrate. It clear that the structure became as island and then cracking started with increase the pulse number. The partials size was in nanoscale and it is seem like (cluster) .at pulse number of 1500 which confirmed the XRD results.

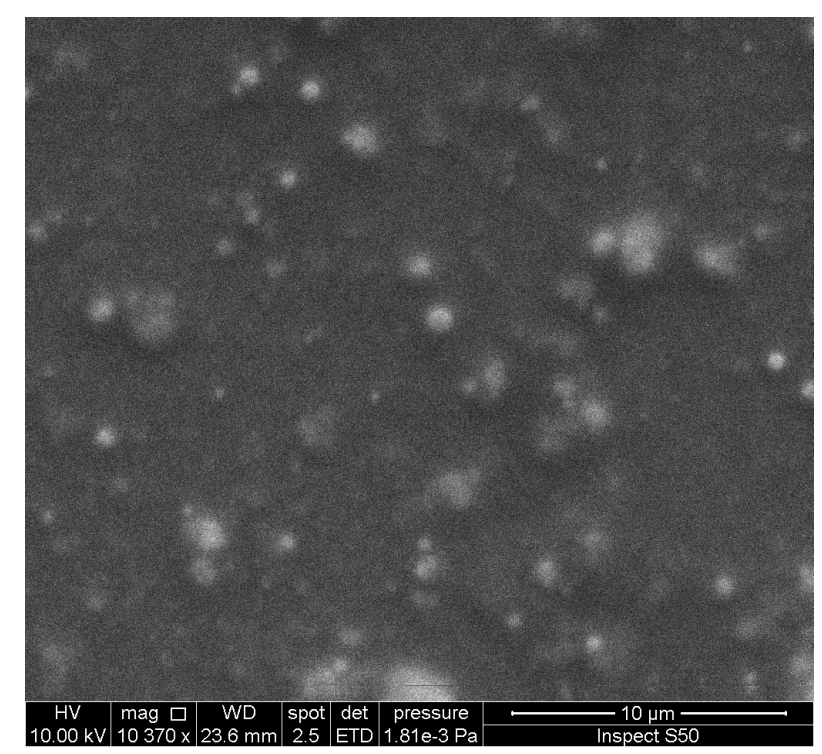

-a-

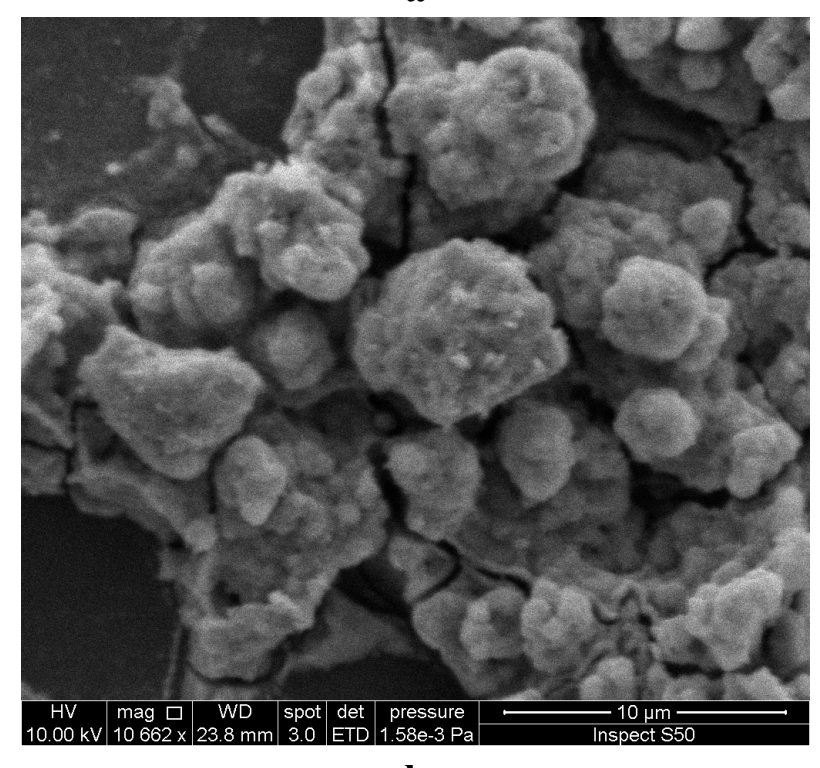

-b- 
6 of 10

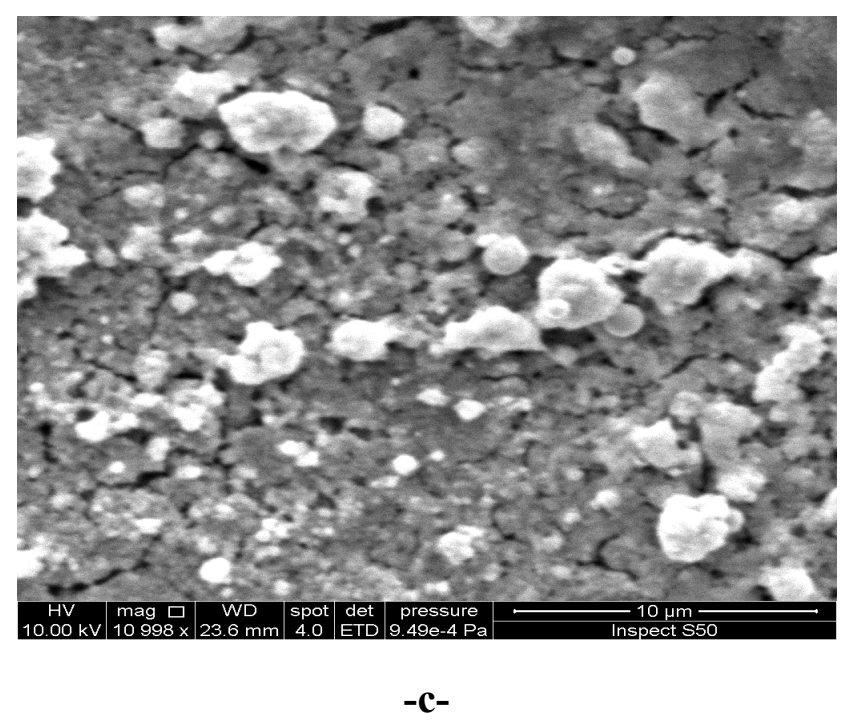

Figure (4) SEM images of $\mathrm{ZnO}$ thin film on glass substrate prepared using PLA method in methanol solvent with energy $700 \mathrm{mj}$ and pulses of a- 1000, b-1500, and c-2000 pulses

Figure (5) show the EDX analysis which confirmed that the $\mathrm{Zn}$ and $\mathrm{O}$ elements is including in the prepared films on glass substrate using PLA method with energy of $700 \mathrm{mj}$ and at a- 1000 , b- 1500 , c- 2000 pulses in methanol solvent.-

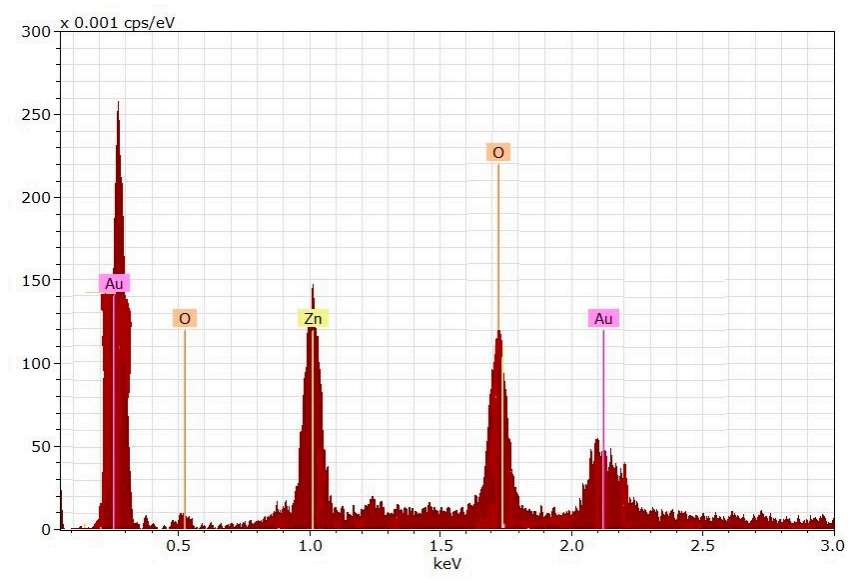

$-\mathbf{a}-$

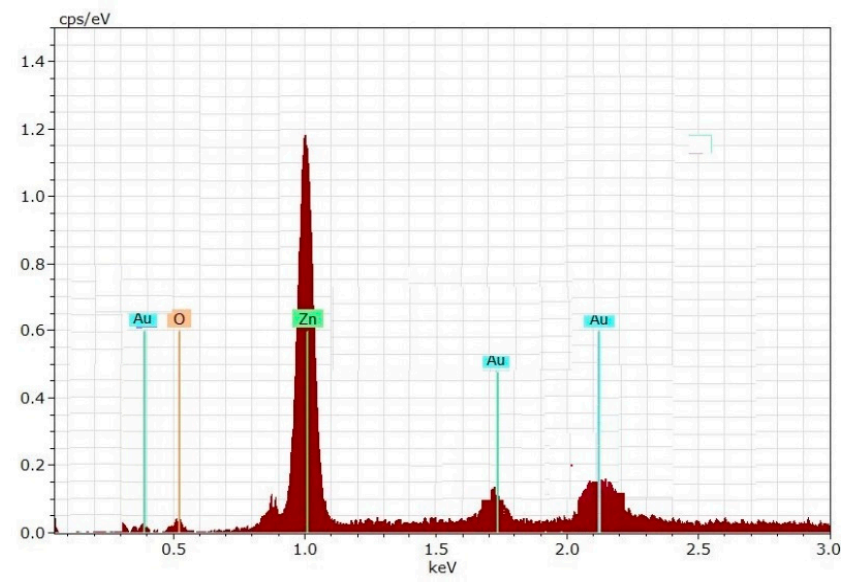

$-b-$ 


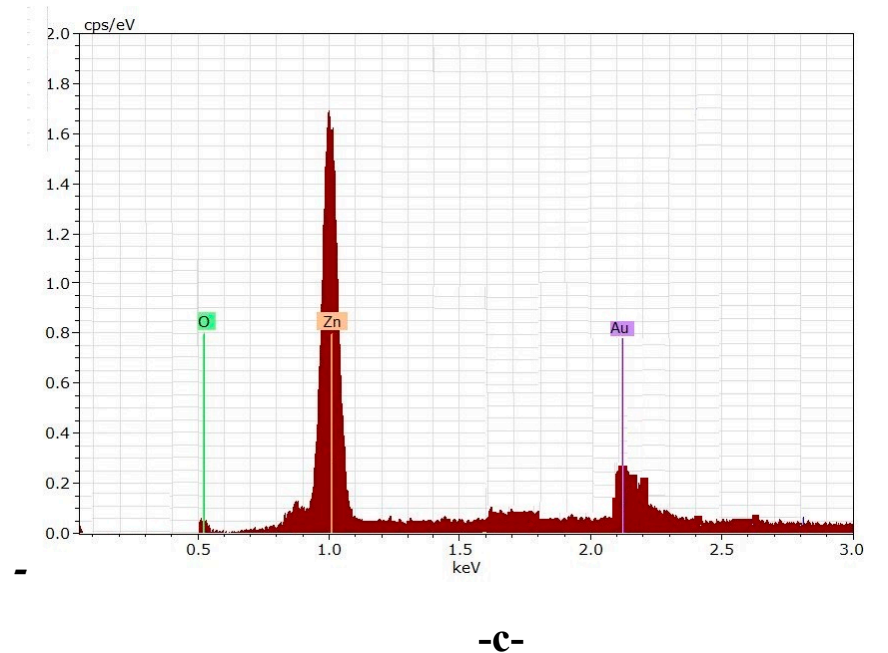

Figure (5) EDX analysis of ZnO thin films prepared by PLA method on glass substrate with energy $700 \mathrm{mj}$ at pulses a-1000, b-1500 and c-2000 pulses in methanol solvent

Figure (6) show SEM images of ZnO nanoparticle prepared on glass substrate using PLA with energy of 600,700 and $800 \mathrm{mj}$ at pulse number of 1500 pulse, dissolved in methanol solution. It clear that the partials size is formed in nanoscale especially at energy $700 \mathrm{mj}$ which seem like (flower) structure, while, at $600 \mathrm{mj}$ the surface look smooth with various crystalline with different size and at $800 \mathrm{mj}$ the surface became more spong with pore size in range of 100-1000 nm .This result is agreement with XRD results and open the door for more studies on this behavior.

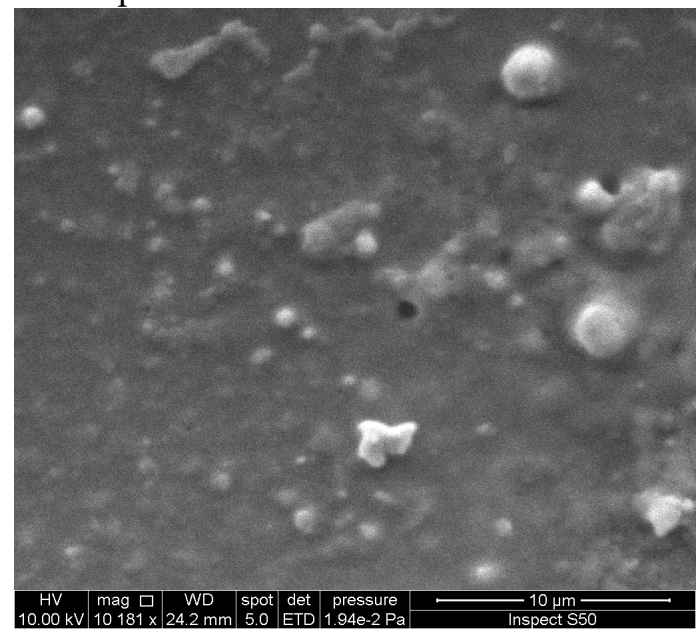

-a-

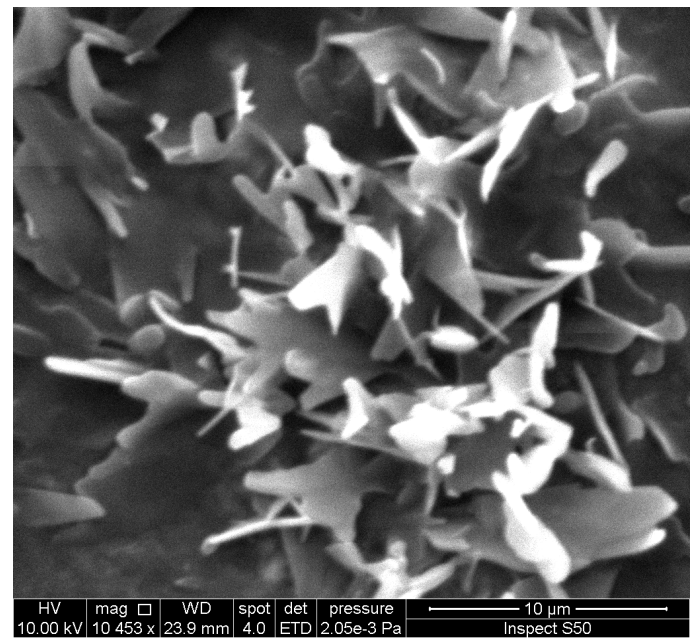

-b- 


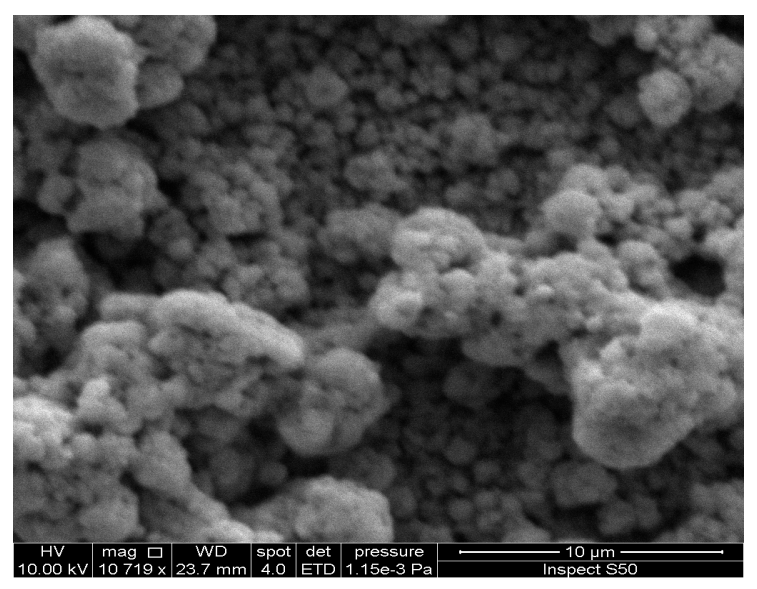

-c-

Figure (6) show SEM images of $\mathrm{ZnO}$ thin film on glass substrate prepared using PLA at pulse number of 1500 and with energy of a-600, b-700 and c-800 mj

Figure (7) show the EDX analysis which confirmed that the $\mathrm{Zn}$ and $\mathrm{O}$ elements is including in the prepared films on glass substrate using PLA method with energy of $700 \mathrm{mj}$ and at a- 1000, b- 1500 and c- 2000 pulses in distill water solvent.

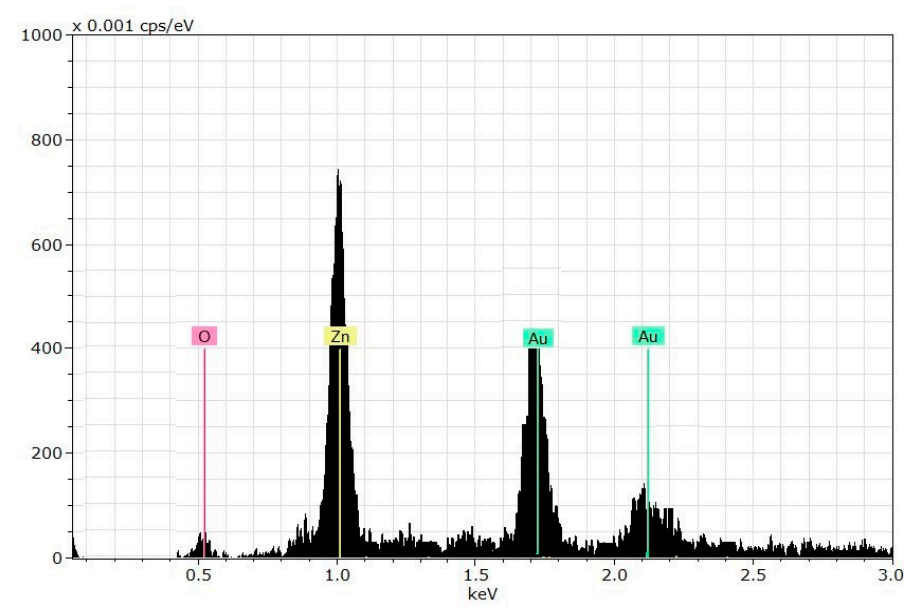

-a-

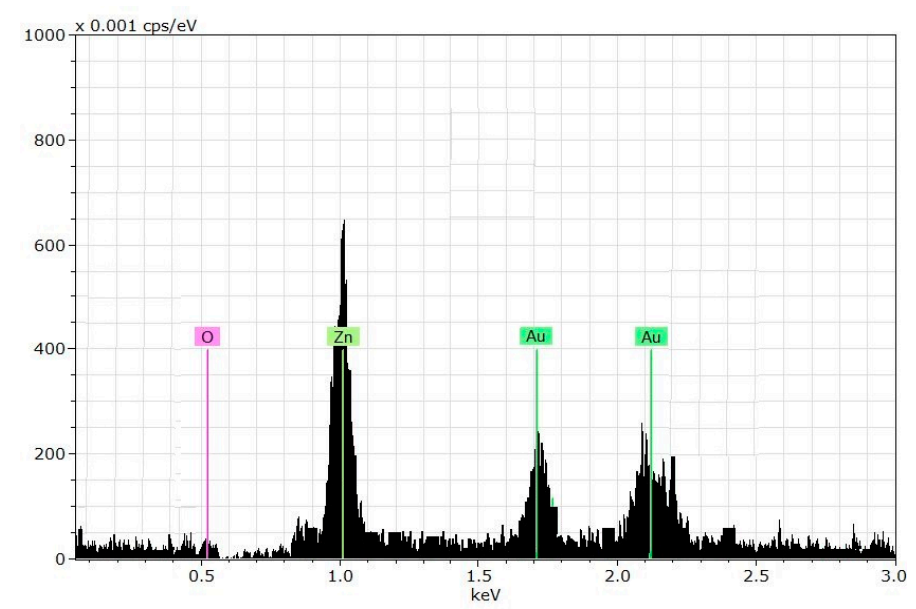

-b- 


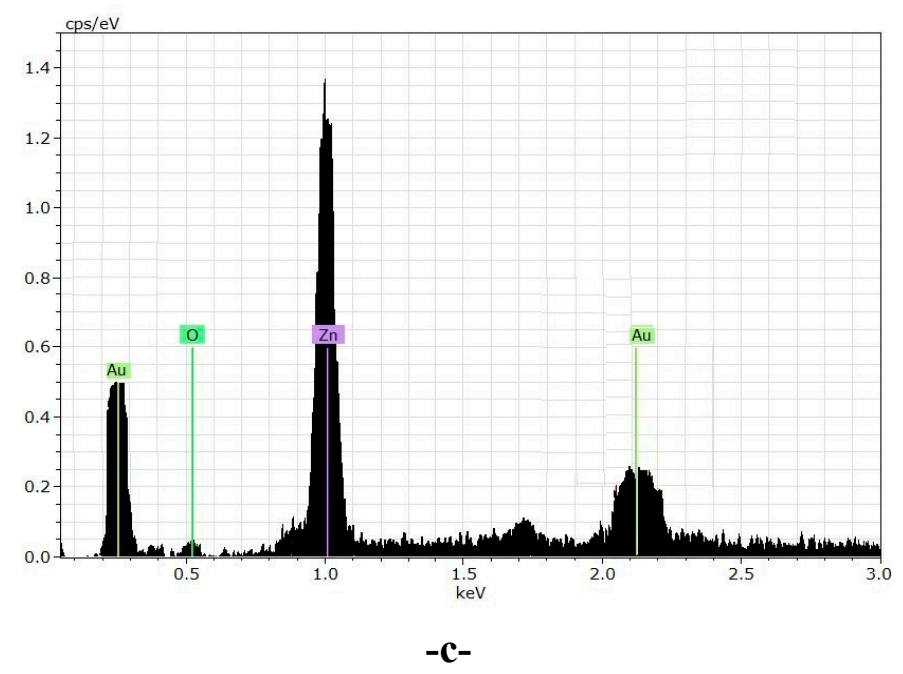

Figure (7) EDX analysis of $\mathrm{ZnO}$ thin films prepared by PLA method on glass substrate with energy of $\mathrm{a}-600, \mathrm{~b}-700$, and c-800 $\mathrm{mj}$ in methanol solvent.

Figure (4-13) show SEM images of $\mathrm{ZnO}$ thin film prepared using PLA with pulse laser ablation, with fixed energy of $700 \mathrm{mj}$ and at Pulse 2000 dissolved in methanol solution, porous silicon substrate. It clear that the surface have pores with different size and different wall in surround and partials size was in nanoscale.this result is agreement with XRD results

\section{Conclusion}

$\mathrm{ZnO}$ thin films have been successfully fabricated on glass substrate using pulse laser ablation (PLA) technique and have hexagonal structure with polycrystalline in nature with preferred orientation of (002). Crystalline size was increased with the increasing of the pulses and at energy of $700 \mathrm{~mJ}$ and pulse of 1500 pulse seemed nanostructure like tree leaf. In addition, in all cases, narrow FWHM and no phase change and the films were homogenous and free of defects and contaminations with some island and cluster then cracking started to obtain with the increasing of increase the pulse number.

\section{References}

1. F. Quarantaa, R. Rellaa and P. Siciliano et al."Preparation and characterization of nanostructured materials for an artificial olfactory sensing system", Sensors and Actuators B, 84 (2002) 55-59.

2. A.V. SIngh, M. kumar, R. M. Mehra, A. Wakahara and A.Yoshida," Al-doped zinc oxide (ZnO:Al) thin films by pulsed laser ablation". J. Indian Inst. Sci., 81, (2001), 527-533.

3. Y. Ishikawa, Y. Shimizu, T. Sasaki and N. Koshizaki," Preparation of zinc oxide nanorods using pulsed laser ablation in water media at high temperature". Journal of Colloid and Interface Science, 300, (2006), $612-615$

4. Q. H. Chen and W. G. Zhang," Successive preparation of decorated zinc oxide organic sol by pulsed laser ablation and their luminescence characteristics", j. apsusc, (2006), 06.065.

5. R. K. Thareja and S. Shukla, "Synthesis and characterization of zinc oxide nanoparticles by laser ablation of zinc in liquid. Applied Surface Science, 253, (2007), 8889-8895.

6. R. S. Ajimsha, G. Anoop, A. Aravind, and M. K. Jayarajz," Luminescence from Surfactant-Free ZnO Quantum Dots Prepared by Laser Ablation in Liquid". Electrochemical and Solid-State Letters, 11 (2), (2008), K14-K17.

7. J. M. Cho, J. K. Song, and S. M. Park," Characterization of ZnO Nanoparticles Grown by Laser Ablation of a Zn Target in Neat Water". Bull. Korean Chem. Soc., 30 (7), (2009).

8. I. S. Virt, I. V. Hadzamana, I. S. Bilyka, I. O. Rudyic, I. V. Kuriloc and et al. "Properties of ZnO and ZnMnO Thin Films Obtained by Pulsed Laser Ablation", Oxide Materials for Electronic Engineering" (OMEE-2009), 117 (1), (2010). 
9. R. A. Ismail, A. K. Ali, M. M. Ismail, K. I. Hassoon," Preparation and characterization of colloidal ZnO nanoparticles using nanosecond laser ablation in water", Appl. Nanosci, 1, (2011), 45-49.

10. G. Atanasova, A. Og Dikovska, M. Stankova, P. Stefanov and P A Atanasov, " XPS study of ZnO nanostructures prepared by laser ablation", Journal of Physics: Conference Series, 356, (2012), 012036.

11. D. Nakamura, T. SImogaki, K. Okazaki, M. Higashihata, H. Ikenoue and et al., "Synthesis of Various Sized ZnO Microspheres by Laser Ablation and Their Lasing Characteristics", JLMN-Journal of Laser Micro/Nanoengineering, 8 (3), (2013).

12. H. E. Palma, M. C. López, M. A. C. López and A. R. V. Néstor,"Preparation of zinc peroxide nanoparticles by laser ablation of solid in liquids", Superficies y Vacío September, 28 (3), (2015), 74-77.

13. F. A. Fadhil and I. H. Hadi, "Preparation and characterization of zinc oxide nanoparticles by laser ablation of zinc in isopropanol", Eng. \& Tech. Journal, 33 B, (5), (2015).

14. E. T. Salim, M. A. Fakhri, H. Hassan, Z. T. Salim and A. Z. Mohamed, "Physicochemical properties of ZnO Nanoparticles prepared using low energy low repetition rate Laser system", Sci. Int. (Lahore), 28 (5), (2016), 4501-4506.

15. S. V. Farahan, A. Mahmood and M. Goranneviss, "The effect of laser environment on the characteristics of ZnO nanoparticles by laser ablation". Int. Nano Lett, 6, (2016), 45-49.

16. R. A. Ismail, N. F. Habubi, E. H. Hadi, "Synthesized and characterization of pure and Er+3 doped ZnO nanoparticles by using laser ablation in ethanol". World Scientific News, 33 (2016), 67-78.

17. K. S. Khashan and F. Mahdi, "Synthesis of ZnO: Mg Nanocomposite by Pulsed Laser Ablation in liquid", Surf. Rev. Lett., 0, (2017), 1750101.

(C) 2017 by the authors. Licensee Preprints, Basel, Switzerland. This article is an open access article distributed under the terms and conditions of the Creative Commons by Attribution (CC-BY) license (http://creativecommons.org/licenses/by/4.0/). 